\title{
Knowledge, Attitude and Practice Regarding Micronutrients and its Impact on Oral Health Status
}

\author{
${ }^{1}$ Sangeeta Pandey , ${ }^{2}$ Divya Mittal \\ ${ }^{1}$ Associate Professor and Head, \\ ${ }^{2} \mathrm{PG}$ Food Science and Nutrition student \\ Department of Nutrition and Dietetics, Mount Carmel College, \\ Autonomous, Bengaluru, Karnataka
}

\begin{abstract}
The oral cavity is the pathway to the rest of the body, so any problems in the oral cavity can profoundly affect appetite and ultimately dietary intake. The aim of the study was to assess the Knowledge, attitude and practice of dietary habits on oral health among the rural and urban study subjects. A cross sectional study was conducted among 200 study subjects (100 urban and 100 rural). The data was collected by administrating a self- structured questionnaire to the respondents. Statistically significance difference at $5 \%$ level was observed between the urban and rural study subjects $(82.9 \%$ and $72.6 \%)$ regarding the overall mean knowledge on acidic foods related to oral health. The overall mean attitude towards micronutrient consumption between the urban $(\mathbf{9 0 . 4 \%})$ and rural $(\mathbf{8 0 . 9 \%})$ study subjects was found to have statistical significance $(\mathbf{p}<0.05)$. Higher adequacy was seen in rural study subjects in consumption of Vitamin-D $(\mathbf{8 0 . 4 \% )}$ ) and phosphorus $(\mathbf{5 6 . 2 \%})$ as compared to that of urban study subjects vitamin-D (58.9\%) and phosphorus $(55.6 \%)$ consumption respectively. A higher number of rural respondents $(\mathbf{7 5 \%})$ had better oral health status as compared to the urban $(65 \%)$ study subjects. The study indicated that the rural study subjects had a lack of sufficient knowledge, attitude of oral health and dietary habits as compared to the urban study subjects.
\end{abstract}

Key Words: Oral health, Dietary habits, Acidic foods, Micronutrient, Dental Caries.

\section{INTRODUCTION}

According to WHO 2012, Oral health is defined as "being free of chronic mouth and facial pain, oral and throat cancer, oral sores, birth defects such as cleft lip and palate, periodontal (gum) disease, tooth decay and tooth loss, and other diseases and disorders that affect the mouth and oral cavity." The most common and prevalent chronic disease worldwide is dental caries. The management of dental caries can be done by preventing the risk factor's and treatment according to the patient's profile. The diet high in sugar products, absence of balanced diet also leads to demineralization of teeth. Nutrition being a significant component of oral health, clearly explains the synergism between nutrition and oral health. The oral cavity is the pathway to the rest of the body, so any problems in the oral cavity can profoundly affect appetite and ultimately diet. Diet influences the health of the oral cavity, conditioning the onset of caries, the development of the enamel, the onset of dental erosion, the state of periodontal health, and of the oral mucous in general [15]. Many Studies have shown that there are greater risk of health conditions like type 2 diabetes, heart diseases, and obesity due to lower, or acidic, $\mathrm{pH}$ levels. Whereas studies have also shown that the improvement in memory and cognition, reduced pain, healthy oral health and lower risk of hypertension, and stroke is due to higher, or alkaline, $\mathrm{pH}$ levels. Health of teeth's and gums are directly affected due to the $\mathrm{pH}$ level in the mouth.

The diet plays an important role in the oral health. The growth, development, maintenance and repair of healthy oral teeth depend upon the proper availability of proper nutrients. The vitamins, which are relevant to oral health, are folate, Vitamin B complex, Vitamin A, C, and D. Both the soluble and insoluble vitamins are important for oral health, maturation of teeth and oral tissues. Vitamin A is important for the development of teeth, especially in the formation of enamel and dentin.

Overall objective was to study the impact of dietary habits on oral health in urban and rural adults and to know their KAP regarding food habits leading to poor oral health.

\section{II.METHODOLOGY}

Dental caries is the most common chronic disease globally and have a significant impact on an individual's social life. The development of caries and periodontal related problems are influenced by various factors such as oral hygiene, nutrition, dietary habits and substance abuse. Chronic diseases like periodontitis lead to tooth loss, which in turn impacts the individual physically, emotionally and financially. Hence, the overall aim of the study was to assess the knowledge, attitude and practice of dietary habits and its imp act on dental health.

The present study was a cross sectional study for which the subjects were chosen on the basis of purposive random sampling. A total of 200 subjects were selected of which 100 were from the rural population and 100 from the urban population. Subjects were selected from different parts of Bangalore and Devanhalli village. Inclusion criteria includes adults between the age limit of 21-65 years and both males and females who were willing to participate in the study. 
A pre-designed questionnaire was used to collect data on the knowledge, attitude and practice on oral health and nutritional status in the adult population. It was also used to collect data on the food consumption pattern of the subjects to study the micronutrient intake. The questionnaire comprised of 4 components:

General Information consisted of their name, age, gender, and educational qualification, place of residence, occupation and socio-economic status. Food Habits section was designed to seek information on their knowledge and attitude towards acidic and alkaline foods, questions aimed at understanding their knowledge of micronutrients and their sources.The 24-h dietary recall is an open-ended method intended to report detailed information about all foods and beverages consumed by a respondent, in the preceding $24 \mathrm{~h}$ or over the previous day [1]. This section aimed at gathering information about the respondent's dietary consumption in the past 24 hours.Food frequency questionnaire included frequency of consumption of all the five food groups i.e. Cereals, Pulses, Fruits and Vegetables, Milk and Meat Products and Fats and Oils was captured. In addition to these, the frequency of consumption of processed foods, sweets and bakery products were also included. The oral health assessment tool is the first step in helping to maintain a resident's oral health. The tool was designed by [3]. It consists of a visual inspection using 8 categories of oral health: Lips, tongue, gums and tissues, saliva, natural teeth, dentures, oral cleanliness, dental pain.

\section{III.RESULTS AND DISCUSSION}

The overall aim of the study was to assess the knowledge, attitude and practice of both the urban and rural study subjects on oral health. The data was collected from 200 study subjects of which 100 were from rural and 100 from the urban area belonging to the age group of 21-65 years.

Table 1: Socio demographic characteristics of the study subjects

\begin{tabular}{|c|c|c|c|c|c|c|c|c|}
\hline \multirow{3}{*}{ Characteristics } & \multirow{3}{*}{ Category } & \multicolumn{6}{|c|}{ Respondents } & \multirow{3}{*}{$\begin{array}{l}' \chi 2 ' \\
\text { Test }\end{array}$} \\
\hline & & \multicolumn{2}{|c|}{$\operatorname{Urban}(\mathrm{n}=100)$} & \multicolumn{2}{|c|}{ Rural (n=100) } & \multicolumn{2}{|c|}{ Total $(n=200)$} & \\
\hline & & $\mathrm{N}$ & $\%$ & $\mathrm{~N}$ & $\%$ & $\mathrm{~N}$ & $\%$ & \\
\hline \multirow[t]{4}{*}{ Age group (years) } & $21-25$ & 30 & 30.0 & 28 & 28.0 & 58 & 29.0 & \multirow{4}{*}{$8.24 *$} \\
\hline & $26-35$ & 41 & 41.0 & 25 & 25.0 & 66 & 33.0 & \\
\hline & $36-45$ & 13 & 13.0 & 22 & 22.0 & 35 & 17.5 & \\
\hline & $46-65$ & 16 & 16.0 & 25 & 25.0 & 41 & 20.5 & \\
\hline \multirow[t]{2}{*}{ Gender } & Male & 50 & 50.0 & 50 & 50.0 & 100 & 50.0 & \multirow[b]{2}{*}{$0.00^{\mathrm{NS}}$} \\
\hline & Female & 50 & 50.0 & 50 & 50.0 & 100 & 50.0 & \\
\hline \multirow[t]{3}{*}{ Food habit } & Vegetarian & 22 & 22.0 & 1 & 1.0 & 23 & 11.5 & \multirow[t]{3}{*}{$1.89^{\mathrm{NS}}$} \\
\hline & Ovo-vegetarian & 20 & 20.0 & 2 & 2.0 & 22 & 11.0 & \\
\hline & Mixed diet & 58 & 58.0 & 97 & 97.0 & 155 & 77.5 & \\
\hline \multirow[t]{4}{*}{ Socio economic status } & Upper & 18 & 18.0 & 5 & 5.0 & 23 & 11.5 & \multirow{4}{*}{$32.77 *$} \\
\hline & Upper middle & 60 & 60.0 & 36 & 36.0 & 96 & 48.0 & \\
\hline & Middle & 11 & 11.0 & 17 & 17.0 & 28 & 14.0 & \\
\hline & Lower middle & 11 & 11.0 & 42 & 42.0 & 53 & 16.5 & \\
\hline
\end{tabular}

\section{* Significant at 5\% level, NS: Non-significant}

Table (1) depicts the socio-demographic characteristics of the study subjects participating in the present study. Majority of the subjects $(41 \%)$ belonged to the age group of 26-35 years in urban study subjects whereas, in rural area majority of the subjects (28\%) belonged to 21-25 years. Least number of respondents belonged to 36-45 yrs age group $13 \%$ and $22 \%$ in the urban and rural study subjects respectively. Predominantly $58 \%$ of the study subjects were found to be following mixed diet whereas only $22 \%$ of the study subjects were vegetarian in the urban subjects. On the other hand $97 \%$ of the study subjects followed mixed diet and only $1 \%$ of the study subjects followed vegetarian diet in rural subjects. The socio economic status based on Kuppuswamy's classification [5] in urban subjects showed that maximum (60\%) study subjects belonged to the upper middle class and only $11 \%$ study subjects belonged to the middle and lower middle class whereas in rural study subjects, $42 \%$ study subjects belonged to the lower middle class and only $5 \%$ subjects belong to upper class. A similar study conducted in Chennai with total sample size of 266 between the age group of 21-60 years [5] showed that the socio economic status based on Kuppuswamy's classification in urban areas. Result shows that $52.3 \%$ study subjects belonged to the upper lower class, $19.5 \%$ study subjects belonged to the lower middle class, $11.7 \%$ study subjects belonged to the upper middle class, $9.4 \%$ study subjects belonged to the lower class and only $7 \%$ study subjects belonged to the upper class.

Table 2 :Statement wise Response on Knowledge on Micronutrients

\begin{tabular}{|c|c|c|c|c|c|c|}
\hline \multirow[t]{3}{*}{ No. } & \multirow[t]{3}{*}{ STATEMENT } & \multicolumn{4}{|c|}{ Response (\%) } & \multirow[t]{3}{*}{ 't' Test } \\
\hline & & \multicolumn{2}{|c|}{ Urban $(n=100)$} & \multicolumn{2}{|c|}{ Rural $(\mathrm{n}=100)$} & \\
\hline & & Mean & SD & Mean & SD & \\
\hline a. & Calcium is important for oral health. & 97.5 & 13.1 & 86.5 & 28.3 & $3.53 *$ \\
\hline b. & Vitamin A is important for oral health. & 78.0 & 32.8 & 85.0 & 29.7 & $1.58^{\mathrm{NS}}$ \\
\hline c. & Drinking adequate water is essential for oral health. & 89.0 & 26.2 & 88.5 & 27.4 & $0.13^{\mathrm{NS}}$ \\
\hline d. & Milk and milk products are rich in calcium. & 96.5 & 14.7 & 85.5 & 29.6 & $3.33^{*}$ \\
\hline e. & $\begin{array}{l}\text { Phosphorus and magnesium along with calcium are important for } \\
\text { dental health. }\end{array}$ & 86.5 & 24.5 & 71.0 & 36.4 & $3.54 *$ \\
\hline f. & Too much of tobacco doesn't lead to oral cancer. & 36.0 & 44.4 & 59.5 & 41.9 & $3.85^{*}$ \\
\hline
\end{tabular}

\footnotetext{
* Significant at 5\% level, NS Non-significant,
} 
Table 3 : Overall Mean Knowledge scores of Respondents on Micro nutrients

\begin{tabular}{|c|c|c|c|c|c|c|c|c|}
\hline \multirow[t]{2}{*}{ Respondents } & \multirow[t]{2}{*}{ Sample } & \multirow[t]{2}{*}{ Statements } & \multirow[t]{2}{*}{ Max. Score } & \multicolumn{4}{|c|}{ Knowledge Scores } & \multirow[t]{2}{*}{ 't' Test } \\
\hline & & & & Mean & SD & $\begin{array}{c}\text { Mean } \\
(\%)\end{array}$ & $\mathrm{SD}(\%)$ & \\
\hline Urban & 100 & 6 & 12 & 9.67 & 1.78 & 80.6 & 14.8 & $0.46 \mathrm{NS}$ \\
\hline Rural & 100 & 6 & 12 & 9.52 & 2.88 & 79.3 & 24.0 & \\
\hline
\end{tabular}

\section{NS : Non-Significant,}

The above table (2\&3) represents the knowledge of study subjects regarding micronutrients. Majority of the urban study subjects knew that calcium is important for oral health (97.5\%) and milk and milk products are rich in calcium (96.5\%). Approximately $85 \%$ of the rural subjects had knowledge regarding the same. As compared to calcium, lesser study subjects (86.5\% in urban and $71 \%$ in rural) knew that phosphorus and magnesium are also important. Surprisingly, $36 \%$ of the urban subjects and $59.5 \%$ of the rural subjects did not know that excessive tobacco consumption leads to oral cancer. A significant difference $(\mathrm{p}<0.05)$ was observed in the knowledge of urban and rural study subjects regarding these statements. The overall mean knowledge of the micronutrient in both the urban and rural study subjects was found Non-significant. The knowledge of the micronutrient related to oral health was higher in urban (80.6\%) than that of rural (79.35) study subjects. Similar study conducted [11] with the total study subjects of 51 showed that the one who weren't taking vitamin D and calcium supplementation had fewer bleeding sites, lower gingival index value. A study conducted by Lian et al., in Kuching, Sarawak with the total population of 209 students showed that $52.2 \%$ of the study subjects ( $32.1 \%$ female $\& 20.1 \%$ male) visit the dentist only when they have dental pain. Only $4.3 \%$ (1.9\% female \& $2.4 \%$ male) responded that they never visited dentist [8].

Table 4 : Statement wise Response on Attitude on Micronutrients

\begin{tabular}{|c|c|c|c|c|c|c|}
\hline \multirow[t]{3}{*}{ No. } & \multirow[t]{3}{*}{ STATEMENT } & \multicolumn{4}{|c|}{ Response (\%) } & \multirow{3}{*}{$\begin{array}{c}\text { 't' } \\
\text { Test }\end{array}$} \\
\hline & & \multicolumn{2}{|c|}{ Urban } & \multicolumn{2}{|c|}{ Rural } & \\
\hline & & Mean & SD & Mean & SD & \\
\hline a. & Do you think 4-5 meals per day is essential for good health? & 78.5 & 39.7 & 50.0 & 43.2 & $4.85^{*}$ \\
\hline b. & Do you think that regular meal timing should be followed? & 96.5 & 16.3 & 90.0 & 27.5 & $2.03 *$ \\
\hline c. & Do you think that micronutrients are important for oral health? & 97.0 & 11.9 & 85.5 & 32.0 & $3.37 *$ \\
\hline d. & Do you think water plays an important role in maintaining oral health? & 94.0 & 17.8 & 89.5 & 27.8 & $1.36^{\mathrm{NS}}$ \\
\hline e. & Do you think that milk and milk products are rich in calcium? & 95.5 & 14.4 & 84.0 & 32.5 & $3.24 *$ \\
\hline f. & $\begin{array}{l}\text { Do you think phosphorus and magnesium plays an important role along with } \\
\text { the calcium in maintaining the oral health? }\end{array}$ & 87.0 & 25.2 & 78.0 & 33.6 & $2.14^{*}$ \\
\hline g. & Do you think too much of tobacco leads to oral cancer? & 84.5 & 31.5 & 89.5 & 27.8 & $1.19^{\mathrm{NS}}$ \\
\hline
\end{tabular}

* Significant at $5 \%$ level, NS Non-significant

Table 5 : Overall Mean Attitude scores of Respondents on Micro nutrients

\begin{tabular}{|c|c|c|c|c|c|c|c|c|}
\hline \multirow{2}{*}{ Respondents } & \multirow[t]{2}{*}{ Sample } & \multirow[t]{2}{*}{ Statements } & \multirow[t]{2}{*}{ Max. Score } & \multicolumn{4}{|c|}{ Knowledge Scores } & \multirow[t]{2}{*}{ 't' Test } \\
\hline & & & & Mean & SD & $\begin{array}{c}\text { Mean } \\
(\%)\end{array}$ & $\mathrm{SD}(\%)$ & \\
\hline Urban & 100 & 7 & 14 & 12.66 & 1.78 & 90.4 & 12.7 & $3.49 *$ \\
\hline Rural & 100 & 7 & 14 & 11.33 & 3.37 & 80.9 & 24.1 & \\
\hline
\end{tabular}

* Significant at 5\% level,

The above table $(4 \& 5)$ depicts the attitude of study subjects regarding micronutrients. More than half of the study subjects (78.5\% of urban and $50 \%$ of rural) felt that $4-5$ meals per day are essential for good health. About $97 \%$ of the urban and $85.5 \%$ of the rural study subjects thought that micronutrients are important for oral health. Furthermore, $87 \%$ of the urban and $78 \%$ of the rural study subjects thought that phosphorus and magnesium plays an important role along with the calcium in maintaining the oral health. Statistically, significance difference was observed in urban and rural study subjects regarding the attitude of the micronutrients related to dental health $(\mathrm{p}<0.05)$. The overall mean attitude score of micronutrient between the urban and rural study subjects was found to be statistically significant $(\mathrm{p}<0.05)$. The attitude percentage was higher in urban $(90.4 \%)$ than that of rural $(80.9 \%)$ study subjects. Similar study conducted with 2058 Japanese students showed that a high intake of yogurt may be associated with a lower prevalence of dental caries in young children [14]. A similar study conducted by Priya et al [2] in Chennai with the total population of 592 children showed that $41 \%$ of the subjects were not aware about bleeding gums, only $35.60 \%$ were aware that bleeding gums meant inflamed gums. Another similar study conducted in school of rural south India with the total population of 200 within the age of 13 years showed that $36 \%$ of the study subjects responded that dental health can affect general health and equal number of study subjects believed it did not [5].

A similar study conducted in Beijing, China with total sample size of 1,557 schoolchildren, 1,132 parents, and 352 schoolteachers showed that the percentage of schoolchildren, parents, and schoolteachers who actually used fluoride toothpaste was $88 \%, 86 \%$, and $87 \%$, respectively, and $73 \%$ of parents, and $74 \%$ of schoolteachers confirmed the caries preventive effect of fluoride toothpaste [9]. Similar study conducted in Sweden stated that several respondents lacked knowledge regarding, the use of fluoride toothpaste and the role of fluoride in the caries process [7]. Study suggests that chronic oral infections can pose a risk of diabetes, cardiovascular diseases like stroke, respiratory disease, low birth weight, preterm births [15]. 
Table 6: Mean consumption of Nutrients and its comparison with RDA

\begin{tabular}{|c|c|c|c|c|c|c|c|c|c|}
\hline \multirow[t]{3}{*}{ Nutrients } & \multirow[t]{3}{*}{ RDA } & \multicolumn{3}{|c|}{ Urban $(n=100)$} & \multirow{3}{*}{$\begin{array}{c}\text { Std } \\
\text { ' } t \text { ' } \\
\text { Test } \\
\end{array}$} & \multicolumn{3}{|c|}{ Rural $(n=100)$} & \multirow{3}{*}{$\begin{array}{c}\text { Std } \\
\text { 't ' } \\
\text { Test }\end{array}$} \\
\hline & & \multicolumn{2}{|c|}{ Consumption } & \multirow{2}{*}{$\begin{array}{c}\text { Adequacy } \\
(\%)\end{array}$} & & \multicolumn{2}{|c|}{ Consumption } & \multirow{2}{*}{$\begin{array}{c}\text { Adequacy } \\
(\%)\end{array}$} & \\
\hline & & Mean & SD & & & Mean & SD & & \\
\hline Vitamin-A & 600 & 451.2 & 96.1 & 75.2 & $10.95^{*}$ & 385.3 & 68.4 & 64.2 & $22.18^{*}$ \\
\hline Vitamin-D & 600 & 353.2 & 59.5 & 58.9 & $29.31 *$ & 321.5 & 52.7 & 80.4 & $37.34 *$ \\
\hline Calcium & $400-800$ & 471.0 & 50.0 & 78.5 & $18.25^{*}$ & 437.1 & 55.3 & 72.9 & $20.83 *$ \\
\hline Phosphorous & 700 & 389.0 & 57.8 & 55.6 & $37.47 *$ & 393.4 & 40.0 & 56.2 & $54.18 *$ \\
\hline
\end{tabular}

* Significant at $5 \%$ level,

The mean micro nutrient intake of both the urban and rural study subjects compared with RDA is depicted in table (6).More than $50 \%$ adequacy was found in all of the micronutrients in both the urban and rural study subjects. Percentage adequacy of Vitamin-A in both the urban and rural study subjects was $75.2 \%$ and $64.2 \%$ respectively. The calcium adequacy reaches to the fair percentage of $78.5 \%$ in urban and $72.9 \%$ in rural study subjects. Higher adequacy was seen in rural study subjects in case of Vitamin-D (80.4\%) and phosphorus (56.2\%) as compared to that of urban study subjects vitamin-D (58.9\%) and phosphorus $(55.6 \%)$ respectively. Significance difference at $5 \%$ was very clearly observed between the nutrient intake and RDA of all the micronutrients in both the urban and rural study subjects $(\mathrm{p}<0.05)$. A similar study conducted by Bhat et al., in urban community in Mangalore [2] with the total 858 students stated that most of the study subjects (78\%) were not aware whether they used toothpaste containing fluoride.

Table 7: Classification of Urban and Rural by Overall Oral health assessment tool level

\begin{tabular}{|c|c|c|c|c|c|c|c|c|}
\hline \multirow[t]{3}{*}{ Oral health assessment level } & \multirow[t]{3}{*}{ Scores } & \multicolumn{6}{|c|}{ Respondents } & \multirow{3}{*}{$\begin{array}{l}\chi^{\prime}{ }^{\prime} \\
\text { Test }\end{array}$} \\
\hline & & \multicolumn{2}{|c|}{ Urban } & \multicolumn{2}{|c|}{ Rural } & \multicolumn{2}{|c|}{ Total } & \\
\hline & & $\mathrm{N}$ & $\%$ & $\mathrm{~N}$ & $\%$ & $\mathrm{~N}$ & $\%$ & \\
\hline Healthy & 0 & 35 & 35.0 & 19 & 19.0 & 54 & 27.0 & \\
\hline Changes & $1-8$ & 65 & 65.0 & 78 & 78.0 & 143 & 71.5 & $8.92 *$ \\
\hline Unhealthy & $9-16$ & 0 & 0.0 & 3 & 3.0 & 3 & 1.5 & \\
\hline Total & & 100 & 100.0 & 100 & 100.0 & 200 & 100.0 & \\
\hline
\end{tabular}

* Significant at $5 \%$ level, $\quad \chi^{2}(0.05,2 \mathrm{df})=5.991$

*Healthy score $0=$ Lips, Tongue, Gums and tissue, Saliva, Natural teeth, Dentures, oral cleanliness, Dental pain.

*Changes 1= Lips, Tongue, Gums and tissue, Saliva, Natural teeth, Dentures, oral cleanliness, Dental pain.

*Unhealthy 2= Lips, Tongue, Gums and tissue, Saliva, Natural teeth, Dentures, oral cleanliness, Dental pain.

The above table (7) represents the overall oral health of both the urban and rural study subjects. It was observed that $35 \%$ of the urban and $19 \%$ of the rural study subjects had good oral health. A higher number of respondents in the rural (78\%) showed some changes as compared to the urban $(65 \%)$ study subjects. The difference was observed in the overall score of the urban and rural study subjects regarding oral health assessment was statistically significant $(\mathrm{P}<0.05)$. Similar study conducted in rural areas of kanchipuram showed that a greater number (44\%) of students brushed their teeth twice daily [13]. Another similar study conducted in Panchkula, India with the total population of 440 within the age of 12 years showed that majority (82.3\%) of the participants felt $t$ hat daily cleaning of teeth can prevent dental caries [10]. A study conducted by Lian et al., in Kuching, Sarawak stated that most of the study subjects practiced tooth brushing in the morning (80.4\%) and before going to bed.(80.4\%) and only one third responded that they brush their teeth in the noon [8].

Table 8: Correlation between Micronutrient and overall Oral health.

\begin{tabular}{|c|l|c|c|}
\hline \multirow{2}{*}{ No. Nutrients } & \multicolumn{2}{|c|}{ Correlation coefficient (r) with Oral health } \\
\cline { 3 - 4 } & & Urban & Rural \\
\hline 1 & Vitamin-A & -0.016 & -0.259 \\
\hline 2 & Vitamin-D & +0.098 & -0.051 \\
\hline 3 & Calcium & +0.059 & -0.159 \\
\hline 4 & Phosphorous & +0.057 & +0.047 \\
\hline
\end{tabular}

The above table (8) depicts the association between micronutrient consumption levels with oral health. It is evident that there exists a higher positive correlation for consumption of vitamin $\mathrm{D}(\mathrm{r}=+0.098)$, calcium $(\mathrm{r}=+0.059)$ and phosphorous ( $\mathrm{r}=+0.057$ ) in the urban when compared to rural population. There was a negative correlation of existing between the consumption of Vitamin-A or Oral health in urban $(\mathrm{r}=-0.016)$ and rural $(\mathrm{r}=-0.259)$ study subjects. As far as Vitamin D is concerned, Result showed that there was a positive correlation existing in the consumption of Vitamin $\mathrm{D}$ among urban $(\mathrm{r}=+0.098)$ but there was a negative correlation showed among the rural $(\mathrm{r}=-0.051)$ study subjects. The phosphorus level showed the positive correlation among the urban $(r=+0.05)$ and rural $(r=+0.047)$ study subjects. A study conducted in school of rural south India with the total population of 200 within the age of 13 years showed that majority of the participants thought that oral health did impact daily activities. Eating $(\mathrm{p}=0.001)$, Cleaning teeth $(\mathrm{p}=0.007)$ Speaking $(\mathrm{p}=0.001)$, Smiling $(\mathrm{p}=0.0011)$ were the significant ones [4].

\section{IV.CONCLUSION}

Diet is a major causative factor for caries and enamel erosion. The nutritional status impacts oral health and also the resistance to many oral conditions, including periodontal diseases and oral cancer. More than $50 \%$ adequacy was found in all of the 
micronutrients in both the urban and rural study subjects. It can be concluded from the study that there was a higher positive correlation between consumption of vitamin D, calcium and phosphorous and oral health in the urban when compared to rural population. Interestingly, a higher positive correlation exists among the urban population with respect to consumption of phosphorous in their diets. It was observed that the overall Oral health of the urban study subjects was healthier as compared to the rural study subjects.

\section{REFERENCES}

[1] Aglago, E. K., Landais, E., Nicolas, G., Margetts, B., Leclercq, C., Allemand, P.\& El Ati, J. (2017). Evaluation of the international standardized 24-h dietary recall methodology (GloboDiet) for potential application in research and surveillance within African settings. Globalization and health, 2017,13(1), 35 .

[2] Bhat, P. K., Lingaraj, S. H., \& Aruna, C. N. Assessing the knowledge of dietitians regarding diet and oral health in Bengaluru city. Journal of Indian Association of Public Health Dentistry,2014, 12(2), 119

[3] Chalmers, J., \& Pearson, A. Oral hygiene care for residents with dementia: a literature review. Journal of Advanced Nursing, $2005,52(4), 410-419$.

[4] Ganesh, R., John, J., \& Saravanan, S. Socio demographic profile of oral cancer patients residing in Tamil Nadu-A hospital based study. Indian journal of cancer, 2013, 50(1), 9.

[5] Kuppuswamy, V. L., Murthy, S., Sharma, S., Surapaneni, K. M., Grover, A., \& Joshi, A. Oral hygiene status, knowledge, perceptions and practices among school settings in rural South India. Oral Health Dent Manag, 2014, 13(1), 146-154.

[6] Gibson, S., and Williams, S. Dental caries in pre-school children: associations with social class, toothbrushing habit and consumption of sugars and sugar-containing foods. Caries Research ,1999, 33,101-113

[7] Jensen, O., Gabre, P., Sköld, U. M., \& Birkhed, D. Fluoride toothpaste and toothbrushing; knowledge, attitudes and behaviour among Swedish adolescents and adults. Swed Dent J, 2011, 35(4), 203-13.

[8] Lian, C. W., Phing, T. S., Chat, C. S., Shin, B. C., Baharuddin, L. H., \& Che'Jalil, Z. J. Oral health knowledge, attitude and practice among secondary school students in Kuching, Sarawak. Archives of Orofacial Sciences, 2010, 5(1), 9-16.

[9] Liu, M., Zhu, L., Zhang, B., \& Petersen, P. E. Changing use and knowledge of fluoride toothpaste by schoolchildren, parents and schoolteachers in Beijing, China. International dental journal, 2007, 57(3), 187-194.

[10] Mehta, A., \& Kaur, G. Oral health-related knowledge, attitude, and practices among 12-year-old schoolchildren studying in rural areas of Panchkula, India. Indian Journal of Dental Research, 2012, 23(2), 293.

[11] Miley, D. D., Garcia, M. N., Hildebolt, C. F., Shannon, W. D., Couture, R. A., Anderson Spearie, C. L., \& Civitelli, R. Cross sectional study of vitamin D and calcium supplementation effects on chronic periodontitis. Journal of periodontology,2009, 80(9), 1433-1439.

[12] Priya, M., Devdas, K., Amarlal, D., \& Venkatachalapathy, A. Oral health attitudes, knowledge and practice among school children in Chennai, India. Journal of Education and Ethics in Dentistry, 2013, 3(1), 26.

[13] Pereira, W. D. Knowledge, attitude and practice on oral hygiene measures among students in rural areas: Kanchipuram. The Pharma Innovation, 2017, 6(9, Part F), 382.

[14] Tanaka, K., Miyake, Y., \& Sasaki, S. Intake of dairy products and the prevalence of dental caries in young children. Journal of dentistry,2010, 38(7), $579-583$.

[15] Scardina and Messina. Good Oral Health and Diet. Journal of Biomedicine and Biotechnology, 2011,8 . 